Association for Information Systems

AIS Electronic Library (AISeL)

Wirtschaftsinformatik 2021 Proceedings

Track 20: Management of digital processes \& architectures

\title{
How does Enterprise Architecture support the Design and Realization of Data-Driven Business Models? An Empirical Study
}

Faisal Rashed

Leuphana Universität Lüneburg

Paul Drews

Leuphana Universität Lüneburg

Follow this and additional works at: https://aisel.aisnet.org/wi2021

Rashed, Faisal and Drews, Paul, "How does Enterprise Architecture support the Design and Realization of Data-Driven Business Models? An Empirical Study" (2021). Wirtschaftsinformatik 2021 Proceedings. 3. https://aisel.aisnet.org/wi2021/EManagementofdigitalprocesses20/Track20/3

This material is brought to you by the Wirtschaftsinformatik at AIS Electronic Library (AISeL). It has been accepted for inclusion in Wirtschaftsinformatik 2021 Proceedings by an authorized administrator of AIS Electronic Library (AISeL). For more information, please contact elibrary@aisnet.org. 


\title{
How does Enterprise Architecture support the Design and Realization of Data-Driven Business Models? An Empirical Study
}

\author{
Faisal Rashed ${ }^{1,2}$ and Paul Drews ${ }^{1}$ \\ ${ }^{1}$ Leuphana University Lüneburg, Institute of Information Systems, Lüneburg, Germany \\ paul.drews@leuphana.de \\ ${ }^{2}$ University of Cambridge, Cambridge, United Kingdom \\ fr386@cam.ac.uk
}

\begin{abstract}
As part of the data evolution, data-driven business models (DDBMs) have emerged as a phenomenon in great demand for academia and practice. Latest technological advancements such as cloud, internet of things, big data, and machine learning have contributed to the rise of DDBM, along with novel opportunities to monetize data. While enterprise architecture (EA) management and modeling have proven its value for IT-related projects, the support of EA for DDBM is a rather new and unexplored field. Building upon a grounded theory research approach, we shed light on the support of EA for DDBM in practice. We derived four approaches for DDBM design and realization and relate them to the support of EA modeling and management. Our study draws on 16 semistructured interviews with experts from consulting and industry firms. Our results contribute to a still sparsely researched area with empirical findings and new research avenues. Practitioners gain insights into reference cases and find opportunities to apply EA artifacts in DDBM projects.
\end{abstract}

Keywords: Data-driven, business model, enterprise architecture.

\section{Introduction}

Data has received considerable attention from business and academia. Latest technological advancements such as cloud, internet of things, big data, and machine learning have contributed to the rise of data-driven business models (DDBM) as an emerging phenomenon [1]. DDBMs are characterized by data as a key resource, data processing as a key activity, or both [2,3]. Novel opportunities appear for organizations to monetize their data. Especially incumbent companies, resting on tremendous amounts of data, are expected to develop new and transform existing business models. However, the failure rate of big data and artificial intelligence projects remains disturbingly high [4].

Considering the high dependency on big data analytics, DDBM deployment implies information system design and implementation, which requires different support in design and realization compared to offline business model innovation [5]. Introducing

16th International Conference on Wirtschaftsinformatik,

March 2021, Essen, Germany 
new DDBM requires deep intervention in the entire organizational structure. The current (as-is) architecture must be well understood and the desired target (to-be) architecture, embedding the DDBM, must be crucially planned. The enterprise architecture (EA) practice is concerned with the aforementioned. EA has proven its potential in many IT-related projects and is deeply rooted in the information system body of knowledge. By providing artifacts such as meta models, frameworks, and management methods, EA supports transparency building on an organization's key components, from business, data, application to the technology level. Furthermore, EA helps to manage the architecture towards common vision [6].

Research on DDBMs is still in its infancy, with most contributions emerging in the past five years $[1,5]$. Practitioners face several challenges in DDBM deployment [4, 7], from identifying relevant opportunities, proceeding with evaluation and ultimately implementing the DDBM [5]. Scholars have started to combine the two lenses of EA and DDBM in order to support DDBM deployment [3]. However, existing literature has examined the intersection from a conceptual standpoint. In this paper, we question the underlying assumption of the existing literature about how EA can be beneficial for DDBM design and realization by conducting empirical research. We want to investigate how EA modeling and management supports DDBM design and realization in practice. Accordingly, our study focuses on the following research question: How does enterprise architecture support the design and realization of data-driven business models? To answer this question, we conducted 16 semi-structured interviews with experts from consulting and industry firms working on DDBM projects in North America, Europe, and the Asia Pacific. Based on these interviews and triangulation data from publicly available sources, we collected 19 cases. We derived four approaches for DDBM design and realization and present for each the support from EA modeling and management.

In the next section, we provide an overview of the theoretical background and related work in the intersection of EA and DDBM. We then describe how we conducted the semi-structured interviews. The cases we gathered will be presented before describing the approaches for DDBM deployment and EA support along the process. Ultimately, we discuss our findings and conclude by discussing future research avenues.

\section{Background and Related Work}

\subsection{Big Data Analytics and Data-Driven Business Models}

The research on big data is deeply rooted in the information system discipline [7-10]. However, the term under which it was examined has evolved in the past decades from business intelligence, business analytics, and big data to big data analytics (BDA) [11]. In this context, the potential value contribution of data has been researched in three major areas, namely improved decision making, enhanced products and services, and new business models [12]. For the latter, the latest technological advancements have contributed to the urge for new DDBMs. Since 2014, a significant number of papers have been published dealing with the need for DDBM research [1]. Accordingly, 
several definitions of DDBM have been proposed by scholars. All point out that data has to be an essential component of the business model. For example, Hartmann, Zaki, Feldmann, and Neely [2] define DDBM as "a business model that relies on data as a key resource". Bulger, Taylor, and Schroeder [13, 14] and Brownlow, Zaki, Neely, and Urmetzer $[13,14]$ similarly highlight the fundamental role of data for DDBMs. Since there is no clear threshold of data utilization for a DDBM, Schüritz and Satzger [15] argue that companies alter from a traditional business model to a DDBM, with increased use of data for the value proposition. In the context of our research, we distinguish between enhancements of existing business models and new DDBMs that are centered on data (data as a key resource and/or data processing as a key activity) [3]. Research on DDBM is thriving but still in an early stage [1]. The latest efforts in academia have focused on extending the most popular business model canvas framework to the special needs of data-driven businesses [2, 16, 17].

\subsection{Enterprise Architecture}

Research on enterprise architecture can be traced back to the Zachman framework from 1980, which provides an ontology for modeling the fundamental structure of an organization and its information systems [18]. Over the past decades, EA has become essential for many organizations to support technology-driven transformations as it helps maintain an overview of complex sociotechnical systems. The Federation of Enterprise Architecture Organizations defines EA as "a well-defined practice for conducting enterprise analysis, design, planning, and implementation, using a comprehensive approach at all times, for the successful development and execution of strategy" [19]. A more narrowed definition of EA has been provided by the Open Group, which is in line with the ISO/ICE/IEEE Standard 42010 of architecture definition, that is, "the structure of components, their inter-relationships, and the principles and guidelines governing their design and evolution over time" [20]. We acknowledge that researchers and practitioners sometimes refer to EA as the practice and sometimes as the actual architecture of an organization. We use the term EA for the practice comprising the related modeling techniques, frameworks, and management function within an organization (EA management). The actual architecture of an organization is noted as as-is architecture, while planned future states are called to-be architecture [3, 21]. EA has proven its potential in improving information system efficiency and effectiveness. It is a critical component for strategic planning, top management decision making, and project management [22]. EA provides artifacts, such as meta-models, frameworks, tools, guiding principles, and management methods to support the evolution of an organization towards a target state. The key components of an organization and their interdependencies are represented in EA models [23]. The models are based on meta-models and deal with either the current state (as-is) or the desired state (to-be) of the enterprise. The EA management function supports the transition from the as-is to the to-be state through several intermediate architecture stages [3]. 


\subsection{Related Work}

To identify the potential relevant related work on the intersection of EA and big data analytics, we conducted a literature review [24]. We queried the following databases with keyword searches: AIS Electronic Library, EBSCO Host Business Source Complete, Google Scholar, IEEE Xplore, JSTOR, Science Direct, and Web of Science. We selected the keywords "enterprise architecture" and "big data". To further extend the literature search, the terms "data-driven" and "analytics," which are associated with "big data" were integrated into the search as well. This led to a total of three strings ("enterprise architecture" and "big data", "enterprise architecture" and "data-driven", "enterprise architecture" and "analytics") for our database queries. We screened all hits based on their title and abstract. Though it limits reproducibility, we included the first 100 search hits from google scholar as an additional source. After reducing irrelevant, duplicate, and non-peer-reviewed articles, a total of 16 articles remained, which we analyzed based on their full text. Additionally, we conducted a backward and forward search.

Table 1. Literature Search

\begin{tabular}{|c|c|c|c|}
\hline Database & Hits & Results & Relevant \\
\hline$A I S$ & 10 & 3 & 0 \\
\hline EBSCO & 5 & 0 & 0 \\
\hline Google Scholar & 100 & 6 & 0 \\
\hline IEEE & 35 & 5 & 2 \\
\hline JSTOR & 0 & 0 & 0 \\
\hline Science Direct & 13 & 1 & 0 \\
\hline Web of Science & 14 & 1 & 0 \\
\hline
\end{tabular}

The results of our literature review revealed a large number of contributions examining EA support for BDA. Scholars have investigated how EA modeling and management can support the design and implementation of BDA [22, 25, 26]. However, with the objective to identify articles focusing on EA support for DDBM, only two contributions remained. First, Vanauer et al. presented a methodology for DDBM design and realization by combining EA and business model canvas techniques. Their theoretical methodology comprises two phases and addresses two different approaches for DDBM deployment. Second, Rashed and Drews have conducted a systematic literature review to illustrate the potential support areas of EA for DDBMs. Furthermore, they have derived 42 DDBM-related EA concerns structured along the business model canvas fields [3]. Both contributions highlight the vast potential of interlinking the rich discipline of EA with the emerging demand of DDBM. However, both articles are purely conceptual with no empirical grounding. We address this research gap an examine EA modeling and management support for DDBM design and realization with a qualitative-empirical study. 


\section{$3 \quad$ Methodology}

The goal of our study is to empirically examine the support of EA modeling and management for DDBM design and realization. Considering the novelty of DDBM for academia and practice, we planned to conduct an explorative qualitative study. Our approach is to derive theory by building upon the grounded theory approach proposed by Corbin and Strauss [27]. We conducted semi-structured interviews with experts from consulting and industry firms to develop explanatory theory, the second type of theory according to Gregor [28]. Each interviewee has a track record of data monetization projects. The data was analyzed as we proceeded with the data collection. We adjusted the interview guide based on our experience from the first interviews and once again after one third was conducted. Choosing a semi-structured interview approach allowed us to set the direction of our research as we collected the data. Drawing on the recommendations from Myers and Newman allowed us to foresee common pitfalls of qualitative interview research [29].

The unit of our analysis are cases of companies that design and realize DDBMs. To understand how EA modeling and management support DDBM design and realization, we structured our interview questions along two phases, namely DDBM design and realization. These phases have been derived from the literature on DDBM design and realization $[30,31]$. We sharpened our questions as we proceeded. In the interviews, we asked the participants about the background and context of the project, the general support from EA, and the DDBM design and implementation phase. We documented their experience along with the case examples.

Between November 2019 and May 2020, we conducted 16 semi-structured expert interviews. All interviews have been recorded, transcribed, and coded by the authors. Except for IP 5, which was a physical meeting, all remaining interviewees have been conducted remotely via internet communication tools. We started with an initial list of interviewees leveraging our professional network, who named well-fitting candidates enjoying expert reputation. Each interviewee has a track record of DDBM projects. This allowed us to get the perspectives of cultural, gender, and regional diverse set of practitioners. Our interviewees have extensive experience in cross-industry firms as well as consulting firms with different specialization. This includes candidates from leading consulting firms, namely McKinsey, Bain, Boston as well as big four companies and large IT consulting firms. We included practitioners from various levels but focused on senior management after the first results demonstrated their broader perspective on the perceived factors (less senior tend to focus on one work package). We acknowledged that our interviewees have different backgrounds and expertise, we adjusted the questions as required. For example, our interviewees had either a stronger business or IT view on the cases they reported. Analyzing the interviewees as we proceeded and asking for further interview candidates allowed us to look for specific experiences, which we might have missed. For example, after the eighth interview, we acknowledged a regional restriction having only European cases collected. We then specifically asked for cases outside of Europe. Similarly, we emphasized the female perspective after taking into account the male dominance. An overview of the candidates' list is illustrated in table 2 . 
The interviews were scheduled with a length of 60 minutes. Depending on the course, the interviewee reported from 1 or 2 cases. We asked for "success" and "failure" cases, referring to the DDBM design and realization. Success constitutes the delivery of the project within time, scope, and budget. In the beginning of each interview, we defined the term DDBM and elaborated on the type of cases we were looking for. At the end of each interview, we asked for project documentation and publicly available data sources for triangulation. Furthermore, we applied internet research to gather additional triangulation data.

To construct a coherent theory based on our gathered data, we drew on grounded theory as proposed by Corbin and Strauss [27]. We applied an open coding approach and selected ATLAS.ti for tool support. Not having a specific framework in mind, we conducted the interviews openly. To uncover relationships among the categories, we reassembled the data that was fractured during open coding. For this, we applied axial coding as described by Corbin and Strauss [27]. Based on the EA support our interviewees described along with the case context and taken steps for DDBM design and realization, we further specified our questions and built theoretical constructs. Dimensions that reached great density within the analysis of the first data were asked specifically for in the following interviews. After the ninth interview, we were able to derive four types of approaches for the collected cases. We used the remaining interviews to test our case cluster with the interviewees.

Table 2. Interview candidates

\begin{tabular}{c|l|l|c}
\hline \multicolumn{1}{c}{ IP } & Role & Organization & Experience \\
\hline 1 & Senior Manager & IT Consulting & +8 years \\
\hline 2 & Director & IT Consulting & +20 years \\
\hline 3 & Senior Manager & IT Consulting & +10 years \\
\hline 4 & Director & Insurance Co. & +20 years \\
\hline 5 & Director & MBB & +12 years \\
\hline 6 & Senior Manager & MBB & $+10 \mathrm{y} / \mathrm{PhD}$ \\
\hline 7 & Director & MBB & $+20 \mathrm{y} / \mathrm{PhD}$ \\
\hline 8 & Consultant & IT Consulting & +4 years \\
\hline 9 & Director & IT Consulting & $+15 \mathrm{y} / \mathrm{PhD}$ \\
\hline 10 & Director & IT Consulting & $+20 \mathrm{years}$ \\
\hline 11 & Director & IT Consulting & $+15 \mathrm{y} / \mathrm{PhD}$ \\
\hline 12 & Senior Manager & IT Consulting & $+10 \mathrm{y} / \mathrm{PhD}$ \\
\hline 13 & Director & Public Services & $+12 \mathrm{y} / \mathrm{PhD}$ \\
\hline 14 & Senior Manager & Financial Services & $+10 \mathrm{years}$ \\
\hline 15 & Senior Manager & Big four & +8 years \\
\hline 16 & Senior Manager & Life Science & $+8 \mathrm{y} / \mathrm{PhD}$ \\
\hline
\end{tabular}

We acknowledge the threats to validity. Considering the four types of validity as described by Maxwell [32], we put great effort to ensure our interviewees can speak openly and are not in a conflicting situation. The developed concepts were critically assessed by both authors. We triangulated the interview results with project 
documentation and publicly available data. Furthermore, we discussed our results with four of our interviewees in a second iteration. These interviewees were: IP4, 7, 11, and 13, who reported voluntarily. Their feedback was used to further sharpen our derived design and realization approaches for DDBM. However, we received great support for the developed concepts from these directors and senior managers within industry and consulting firms.

\section{$4 \quad$ Results}

In this chapter, we will first present an overview of the cases that were discussed in the interviews. Second, we describe the reported approaches for DDBM design and realization. Third, the support of EA modeling and management is illustrated for the identified approaches.

\subsection{Case Overview}

Discussing the terms DDBMs and EA at the beginning of our interviews was beneficial for our detailed debates. Furthermore, it gave us an understanding of the divergent interpretation of the term DDBM by practitioners. While some share our view of DDBM as new business model with data as a key resource and/or data processing as a key activity, others interpret the gradual enhancement of the existing business model with data as DDBM as well. Four cases represent DDBMs in line with our interpretation. Our interviewees highlighted the scarcity of latter mentioned cases, as they require a "clear business vision, well understood data and the technological backbone" [IP7]. The remaining cases represent organizational endeavors to gradually enhance technological and analytical capabilities to build the foundation for DDBMs. The term EA was clear to all interviewees. However, in most interviews, we had to emphasize that the EA practice goes beyond the EA department established within an organization. This means, even without the involvement of the mentioned department, EA artifacts can support the DDBM design and realization.

Table 3. Case list

\begin{tabular}{l|lll|l|l|l}
\hline $\boldsymbol{C}$ & IP & Industry & Reg./Glo. & HQ & Motivation & Sponsor \\
\hline 1 & IP1 & Insurance & Local & D & Digital strategy & CDO/CIO \\
\hline 2 & IP2 & FS & Global & AUT & Digital strategy & CDO/CIO \\
\hline 3 & IP2 & FS & Global & AUT & Competitive response & CDO/CIO \\
\hline 4 & IP3 & Insurance & Global & D & Digital strategy & CDO/CIO \\
\hline 5 & IP4 & Insurance & Global & CH & Competitive response & CDO/CIO \\
\hline 6 & IP5 & FS & Global & CH & BU vision & Head of M\&S and CDO \\
\hline 7 & IP5 & FS & Global & CH & BU vision & Head of HR \\
\hline 8 & IP6 & IE & Global & D & Company vision & CEO \\
\hline 9 & IP7 & Insurance & Global & CHN & $\begin{array}{l}\text { Clear business } \\
\text { opportunity }\end{array}$ & CEO \\
\hline 10 & IP8 & Chemicals & Global & D & Digital strategy & CDO/CIO \\
\hline
\end{tabular}




\begin{tabular}{l|l|l|l|l|l|l}
\hline 11 & IP9 & LS & Global & CH & BU vision & Head of R\&D and CDO \\
\hline 12 & IP9 & LS & Global & D & BU vision & Head of M\&S and CDO \\
\hline 13 & IP10 & Insurance & Local & US & Digital strategy & CDO/CIO \\
\hline 14 & IP11 & FS & Global & AUS & $\begin{array}{l}\text { Clear business } \\
\text { opportunity }\end{array}$ & CEO \\
\hline 15 & IP12 & Energy & Local & D & $\begin{array}{l}\text { Clear business } \\
\text { opportunity }\end{array}$ & CEO/CIO \\
\hline 16 & IP13 & PS & Local & D & Digital strategy & CDO/CIO \\
\hline 17 & IP14 & FS & Global & CH & Digital strategy & CDO/CIO \\
\hline 18 & IP15 & LS & Global & D & Digital strategy & CDO/CIO \\
\hline 19 & IP16 & LS & Global & UK & BU vision & Head of R\&D and CDO \\
\hline
\end{tabular}

The gathered cases reflect organizational endeavors to deploy DDBMs. The companies behind these endeavors are predominantly from the insurance, financial services, and life sciences industry. This may be due to the proximity of the core business to data processing [IP7,9,11]. All companies are large size global and local players with origin in Europe, Asia, and the North America. Two of the four DDBM cases comprise European firms and two Asian Pacific firms. The business unit initiating the project was decisive for the expected value and application of the data. For example, the R\&D unit of a pharma company seeks maximization of data value for drug development. This might come from shortened clinical trial phases or identification of new drugs [IP9]. Independent from the initiating business unit, CEO sponsorship and support was reported as vital for the cases. Considering the fragmented and isolated data sources throughout the company, timely data access becomes crucial. The majority of the described cases had CEO or CEO-1 level sponsorship. The quantitative analysis as illustrated in figure 1. The companies behind all reported cases had an EA department established. However, the duties and impact varied among the companies. For 17 cases our interviewees mentioned that EA must play a vital role in DDBM design and realization. Along all cases our interviewees faced EA concerns, regarding transparency of the prevailing architecture, planning of the target architecture and/or managing the transformation from as-is to to-be state. However, for only 10 cases our interviewees stated that EA modeling and management techniques were instrumentalized.

Quantitative analysis of key statements along the 19 cases

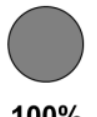

$100 \%$

Stated that EA department was established within the focal organization

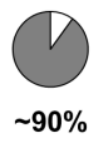

Stated that EA must play a vital role in DDBM design and realization

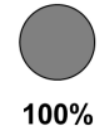

Faced EA concerns in their DDBM design and realization cases

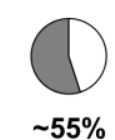

Utilized EA modeling and management practices for their cases

Figure 1. Key statements 


\subsection{Approaches for DDBM Design and Realization}

The support of EA depends on the company context and the approach taken towards DDBM design and realization. Across the 19 cases we have identified four approaches for DDBM deployment. The companies behind the cases, either take a gradual approach or a direct approach. For the first, they start building technology capabilities first or analyze the existing data to develop use cases for DDBMs. For the latter, they either integrate the new DDBM into the existing organizational structures or establish a new DDBM startup. All companies behind the cases had a dedicated EA management function established. Our interviewees commonly reported that EA must play a vital role for DDBM design and realization, regardless if EA fulfilled the requirements or not. With this critical role, EA can become a "bottleneck" for DDBM design and realization, and the EA management function might be actively excluded from the process. In the following, we will describe the EA support along with the four approaches for DDBM design and realization, referring to figure 2.

Technology centric. Seven cases comprise companies that embark on the journey towards DDBM realization by developing technology capabilities first. Business requirements are blurry and derived from high-level use cases. The process is driven by the IT department and initiated with technology selection efforts. Followed by a proof-of-concept phase and ultimately the implementation. EA supports the technology selection by enabling the development of business and technology capability maps that allow an understanding of the required technologies. These models are used to map technology solutions to the target business capabilities [IP1-3, 14,15]. Furthermore, EA models were used to grant transparency on the prevailing data and technology landscape $[I P 1-3,10,13]$. To proceed after the proof-of-concept phase, a formal signoff from the architecture board is required. The proposed solution must comply with the prevailing EA principles and overall target architecture [IP2,3,13-15]. EA methods and models have been used to cascade from capability domains to technology requirements. The EA management function was actively engaged by providing transparency and guidance. EA frameworks and tools have only been partially mentioned. TOGAF has been used for EA documentations [IP2,3,14].

Use case centric. Five cases represent companies that begin with the ideation, prioritization, and sequencing of BDA use cases. The use case development is driven by the business units (BUs), followed by a solution architecture development phase. The designed solution is then prototyped and tested via a minimum viable product phase, which results in an implementation in case of success. In two out of the five cases, the EA management function supported the use case development with models to provide transparency on the data and technology landscape [IP5,16]. Further EA services were required to get sign-offs from architecture boards to proceed with the implementation. EA models were developed for the solution architecture and the implementation roadmap. One consulting firm has applied a self-developed EA method to support the use case and solution architecture development [IP9]. EA frameworks and tools have not been perceived as mentionable. 
DDBM integration. Three cases comprise actual DDBM deployments. The companies behind these cases transformed their existing organizational structure to integrate the new DDBM. The process is initiated with a DDBM design phase, followed by prototyping with a minimum viable product and ultimately implementation. EA models are used to provide transparency over the prevailing data and technology landscape. The models are developed by consulting firms for specific concerns. Standard EA models are only used to derive own models answering the DDBM-related EA concerns. EA models are also developed to envision the solution architecture and guide the implementation. The EA management function is actively excluded from the DDBM design and realization process. The EA services are only required to get formal sign-off from the architecture boards. EA methods, frameworks, and tools have not been perceived as a mentionable component of the design and realization phase [IP6, 11,12].

DDBM startup. In contrast to the latter presented path towards DDBM design and realization, the establishment of DDBM through a new company requires a different approach. A new company must be established. The new team moves the DDBM design and realization in a startup way of working forward. The parental company provides the data. EA support is required to access the data via APIs, providing transparency over data and technology landscape. EA services are required to develop models and find solutions for data extraction. However, the EA management function is actively excluded and perceived as a bottleneck that slows down processes. The new company is staffed with technology experts, capable to design and manage the realization of the startup architecture. The importance of rapidly scalable architecture was emphasized by our interviewee [IP7]. Standard EA methods, models, and tools have not been perceived as mentionable along the process.

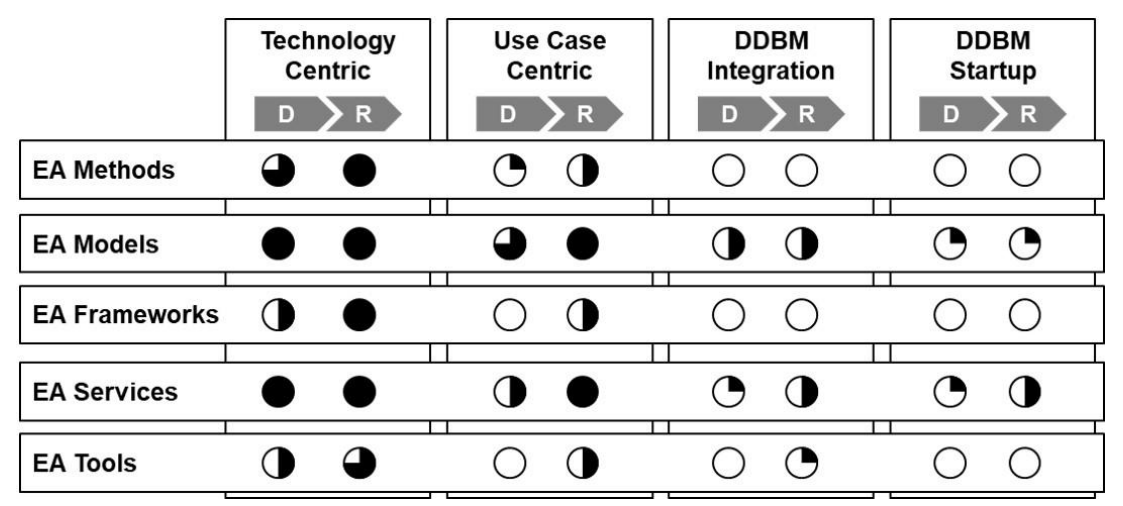

Figure 2. EA support for DDBM design and realization

The highest application of EA artifacts was reported in the technology centric approach for DDBM deployment. EA supports in its traditional role in the integration of new technology, both strategic planning and project realization. The use case centric 
approach requires a different EA support. The traditional EA models, framework, and tools are too complex, and technology-focused for business discussions in individual BUs [IP9,16]. However, our interviewees reported that lightweight models are developed, project-specific together with business users [IP5,9,16]. With the DDBM integration and startup approach, EA is facing new challenges. Traditional models, frameworks, and tools are rarely applied. The EA management function with its principles and standards is perceived as a bottleneck and actively excluded [IP6,7,11,12].

\subsection{Support Gap of Enterprise Architecture for Data-Driven Business Models}

In the previous section, we have described how EA supports the design and realization of DDBMs. The illustration in Figure 2 implies a gap of support for the DDBM Integration and Startup approach. To demonstrate this gap, we have derived the support potentials of EA for DDBM from our interview results as well as from our literature search. Figure 3 illustrates the potential application areas of EA modeling and management for each of the approaches.

EA finds a higher application in the technology centric approach since the traditional EA capabilities are demanded. Technology selection and implementation are driven by the IT department. The use case centric approach is driven by BUs and requires EA support for use case design and realization. For the DDBM integration approach, EA can be beneficial for ideation, solution sketching, and feasibility testing as well as for the implementation. The DDBM startup approach demands from the EA to support agile teams, rapidly proposing, and developing solutions. In contradiction to its traditional role, EA must adapt to a fail fast and learn culture.

\section{Conclusion and Future Research}

The rise of DDBMs brings unique opportunities to organizations to monetize their data. A considerable number of articles has addressed this topic in the literature [1]. However, most companies struggle to implement DDBM projects [4]. Prevailing methods and tools for the deployment of offline business models do not capture the unique perspectives of data and analytics, that DDBM endeavors require [1,5]. Even though EA has proven its potential for IT-related projects, the intersection with DDBMs has not been extensively investigated in the literature [3, 30]. First attempts of combining the two lenses of EA and DDBM, imply underlying assumptions about how EA can be beneficial for DDBM deployment. In this study, we questioned these underlying assumptions and examined how EA modeling and management supports DDBM design and realization in practice. To contribute to research, we conducted 16 semi-structured interviews with experts from consulting and industry firms, to empirically investigate the EA - DDBM intersection. We derived four approaches for DDBM design and realization and described for each the support of EA modeling and management. Our results have revealed that EA is a common practice in many companies. Accordingly, is the expectation of EA support for DDBM high. All our 


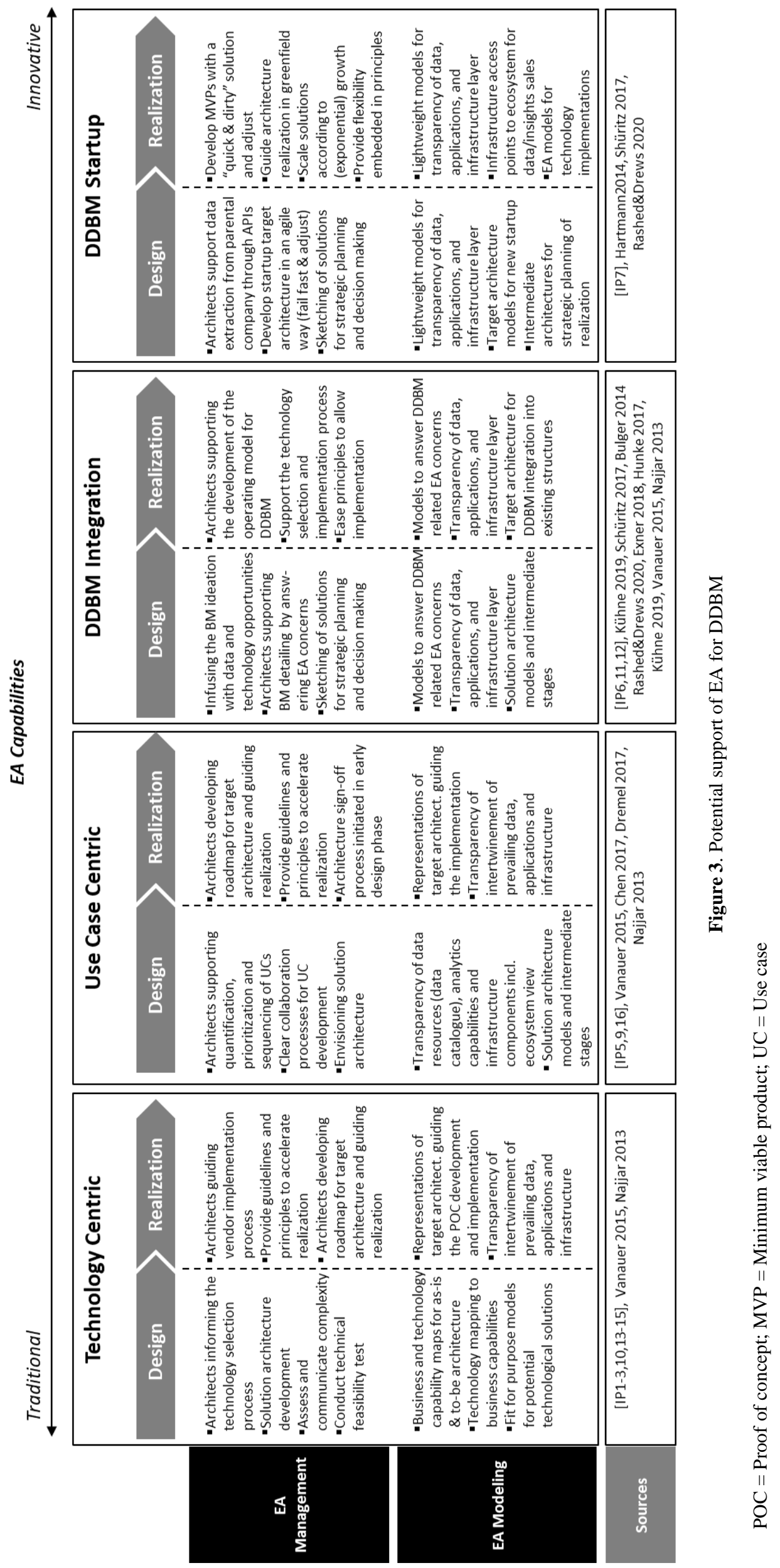


interviewees have faced EA concerns along their DDBM journey. However, we found that regardless of the potential support opportunities, many practitioners perceive the EA practice as a bottleneck for innovative project setups like DDBM deployment. Consequently, we have found that EA was utilized high in the technology centric approach, which demands the traditional capabilities of EA and is driven by the IT department. While the more innovative settings like DDBM integration and startup approaches have utilized EA only very rarely. The latter approaches are driven by the business with support from IT. Considering the interview results and the existing literature on the intersection of DDBM and EA, it further comes apparent that EA is not leveraged to its full potential in DDBM design and realization.

The results of our research have implications for academia and practice alike. For academia, our contribution is threefold. First, we have presented 19 international DDBM cases and derived four approaches for DDBM deployment. Along these approaches we demonstrated how EA modeling and management are applied in practice to support DDBMs. Second, we revealed the discrepancies between the underlying assumptions of the literature on EA support for DDBM and the practical manifestation. For example, Rashed and Drews [3] describe EA support along one approach for DDBM design and realization. Our findings demonstrate four different approaches with varying demand on EA support. Furthermore, the literature neglects the perceived value from EA by practitioners $[3,30]$. Although a high value potential can be derived from the literature [3], it involves many underlying assumptions that must be questioned when looking into the practical manifestation. Third, by analyzing the literature and conducting empirical research, we have opened new research avenues. Especially for deepened research on EA capabilities to support DDBM design and realization, the role of architects in DDBM endeavors, as well as the perceived value from EA and the negative connotation of a "bottleneck". Future research could investigate the conceptualization of EA as "control point" offering value. For practitioners, the collected cases provide valuable insights into reference projects. The overview of the current literature is beneficial for targeted knowledge development. Additionally, the presented approaches and the respective EA support can be inspiring for EA departments to find new support opportunities.

Our study's results bear some limitations. Drawing upon Maxwell [18], we structure the limitations of our qualitative research along the four proposed types. First, for evaluative limitations, we acknowledge the threat to validity based on the dependency on the individual interpretation of the reported events. Although we have validated the described facts with triangulation data, the threat cannot be completely diminished. Second, for theoretical limitations, we applied a semi-structured interview approach to collect the data open-minded. However, our research was infused by our previous research on the intersection of DDBM and EA. Third, interpretative limitations, the derived approaches are imbued with our interpretation of the data. Although both authors have independently processed the data and the results have been challenged with two directors from management consulting firms, a binding to the interpreter's perspective will remain. Fourth, descriptive limitations, we acknowledge the threat to validity imposed in the description process. In prevention, all results have been written and interpreted by both authors iteratively. The working paper has been sent to two 
interviewees in order to gather additional feedback. Ultimately, we have to emphasize that the number of conducted interviews and collected cases are limited. However, we analyzed the data as we proceeded with the interviews. After the ninth interview, we were able to derive the approaches. The remaining interviews have been used to test our concepts.

Despite the vast potential of applying EA modeling and management concepts for DDBM design and realization, their utilization is limited in practice. We plan to develop a reference model for the design and realization of DDBM under special consideration of the EA practice. Additionally, we opened new research avenues in the directions of EA capabilities to support DDBM design and realization, the role of architects in DDBM endeavors, as well as the perceived value from EA and the negative connotation of a "bottleneck".

\section{References}

1. Wiener, M., Saunders, C., Marabelli, M.: Big-data business models: A critical literature review and multiperspective research framework. J. Inf. Technol. 35, 66-91 (2020).

2. Hartmann, P.M., Zaki, M., Feldmann, N., Neely, A.: Big Data for Big Business? A Taxonomy of Data-driven Business Models Used by Start-up Firms. Cambridge Serv. Alliance. 1-29 (2014).

3. Rashed, F., Drews, P.: Supporting the Development and Realization of Data-driven Business Models with Enterprise Architecture Modeling and Management. In: International Conference on Business Information Systems. Springer International Publishing, Colorado Springs (2020).

4. Redman, T.C.: Do Your Data Scientists Know the 'Why' Behind Their Work? Harv. Bus. Rev. (2019).

5. Fruhwirth, M., Ropposch, C., Pammer, V.: Supporting Data-Driven Business Model Innovations: A Structured Literature Review on Tools and Methods. J. Bus. Model. 8, 1-19 (2020).

6. Winter, R., Fischer, R.: Essential Layers, Artifacts, and Dependencies of Enterprise Architecture. J. Enterp. Archit. 3, 7-18 (2007).

7. Günther, W.A., Rezazade Mehrizi, M.H., Huysman, M., Feldberg, F.: Debating Big Data: A Literature Review on Realizing Value From Big Data. J. Strateg. Inf. Syst. 26, 191-209 (2017).

8. Abbasi, A., Sarker, S., Chiang, R.H.L.: Big Data Research in Information Systems: Toward an Inclusive Research Agenda. J. Assoc. Inf. Syst. 17, 1-30 (2016).

9. Baesens, B., Bapna, R., Marsden, J.R., Vanthienen, J., Zhao, J.L.: Transformational Issues of Big Data and Analytics in Networked Business. MIS Q. 40, 807-818 (2016).

10. Sharma, R., Mithas, S., Kankanhalli, A.: Transforming Decision-Making Processes: a Research Agenda for Understanding the Impact of Business Analytics on Organisations. Eur. J. Inf. Syst. 23, 433-441 (2014).

11. Chen, H., Chiang, R.H.L., Storey, V.C.: Business Intelligence and Analytics: From Big Data to Big Impact. MIS Q. 36, 1165-1188 (2012).

12. Engelbrecht, A., Gerlach, J., Widjaja, T.: Understanding the Anatomy of Data-driven 
Business Models - Towards an Empirical Taxonomy. In: Twenty-Fourth European Conference on Information Systems. pp. 1-15. ECIS, İstanbul (2016).

13. Bulger, M., Taylor, G., Schroeder, R.: Data-Driven Business Models: Challenges and Opportunities of Big Data. Oxford Internet Inst. 1-74 (2014).

14. Brownlow, J., Zaki, M., Neely, A., Urmetzer, F.: Data and Analytics - Data-Driven Business Models : A Blueprint for Innovation, (2015).

15. Schuritz, R., Satzger, G.: Patterns of Data-Infused Business Model Innovation. In: Proceedings - CBI 2016: 18th IEEE Conference on Business Informatics. pp. 133-142. IEEE, Paris (2016).

16. Kühne, B., Böhmann, T.: Requirements for Representing Data-Driven Business Models - Towards Extending the Business Model Canvas. In: Twenty-fourth Americas Conference on Information Systems. pp. 1-10. AIS, New Orleans (2018).

17. Osterwalder, A., Pigneur, Y.: Business Model Generation: A Handbook for Visionaries, Game Changers and Challengers. John Wiley and Sons, Inc., Hoboken (2010).

18. John A. Zachman: Zachman International, https://zachman.com/about-the-zachmanframework, last accessed 2019/11/12.

19. Federation of EA Professional Organizations: A Common Perspective on Enterprise Architecture, (2013).

20. The Open Group: TOGAF, https://www.opengroup.org/togaf, last accessed 2019/10/06.

21. Winter, R., Fischer, R.: Essential layers, artifacts, and dependencies of enterprise architecture. J. Enterp. Archit. 3, 7-18 (2007).

22. Burmeister, F., Drews, P., Schirmer, I.: Towards an Extended Enterprise Architecture Meta-Model for Big Data - A Literature-based Approach. In: Twenty-fourth Americas Conference on Information Systems (AMCIS). pp. 1-10. AIS, New Orleans (2018).

23. Musulin, J., Strahonja, V.: Business model grounds and links: Towards enterprise architecture perspective. J. Inf. Organ. Sci. 42, 241-269 (2018).

24. Vom Brocke, J., Simons, A., Niehaves, B., Reimer, K., Plattfaut, R., Cleven, A.: Reconstructing the Giant: On the Importance of Rigour in Documenting the Literature Search Process. In: European Conference on Information Systems. pp. 2206-2217. ECIS, Verona (2009).

25. Kehrer, S., Jugel, D., Zimmermann, A.: Categorizing Requirements for Enterprise Architecture Management in Big Data Literature. In: 20th International Enterprise Distributed Object Computing Workshop. pp. 98-105. IEEE, Vienna (2016).

26. Lnenicka, M., Komarkova, J.: Developing a government enterprise architecture framework to support the requirements of big and open linked data with the use of cloud computing. Int. J. Inf. Manage. 46, 124-141 (2019).

27. Corbin, J.M., Strauss, A.: Grounded Theory Research: Procedures, Canons, and Evaluative Criteria. Qual. Sociol. 13, 3-21 (1990).

28. Gregor, S.: THE NATURE OF THEORY IN INFORMATION SYSTEMS 1. (2006).

29. Myers, M.D., Newman, M.: The Qualitative Interview in IS Research: Examining the Craft. Inf. Organ. 17, 2-26 (2007).

30. Vanauer, M., Bohle, C., Hellingrath, B.: Guiding the Introduction of Big Data in Organizations: A Methodology with Business- and Data-driven Ideation and Enterprise Architecture Management-Based Implementation. In: 48th Hawaii International Conference on System Science. pp. 908-917. IEEE, Hawaii (2015). 
31. Chen, H.-M., Kazman, R., Garbajosa, J., Gonzalez, E.: Big Data Value Engineering for Business Model Innovation. In: 50th Hawaii International Conference on System Sciences. pp. 5921-5930. IEEE, Hawaii (2017).

32. Maxwell, J.A.: Qualitative Research Design: An Interactive Approach. SAGE, Washington (2013).

33. Najjar, M.S., Kettinger, W.J.: Data Monetization: Lessons from a Retailer's Journey. MIS Q. Exec. 12, 21-32 (2013).

34. Dremel, C., Wulf, J.: Towards a Capability Model for Big Data Analytics. In: 13th International Conference on Wirtschaftsinformatik. pp. 1141-1155. AIS, St. Gallen (2017).

35. Kühne, B., Böhmann, T.: Data-driven Business Models - Building the Bridge Between Data and Value. In: 27th European Conference on Information Systems. pp. 1-16. ECIS, Stockholm \& Uppsala (2019).

36. Kühne, B., Zolnowski, A., Böhmann, T.: Making Data Tangible for Data-driven Innovations in a Business Model Context DSR Methodology View project Service Dominant Architecture View project. In: Twenty-fifth Americas Conference on Information Systems. pp. 1-10. AIS, Cancun (2019).

37. Schüritz, R., Seebacher, S., Dorner, R.: Capturing Value from Data: Revenue Models for Data-Driven Services. In: Proceedings of the 50th Hawaii International Conference on System Sciences (2017). pp. 5348-5357. , Waikoloa (2017).

38. Exner, K., Stark, R., Kim, J.Y.: Data-driven business model: A methodology to develop smart services. In: International Conference on Engineering, Technology and Innovation. pp. 146-154. IEEE, Madeira Island (2018).

39. Hunke, F., Seebacher, S., Schuritz, R., Illi, A.: Towards a process model for data-driven business model innovation. In: 19th Conference on Business Informatics, CBI. pp. 150157. IEEE, Thessaloniki (2017). 